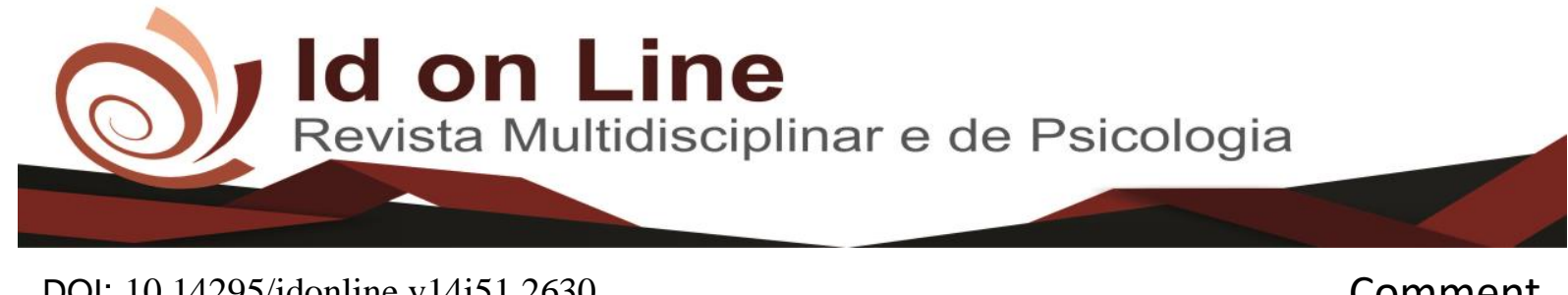

DOI: 10.14295/idonline.v14i51.2630

Comment

\title{
Práticas Pedagógicas na Formação Docente
}

Cleyde Nascimento da Silva ${ }^{1}$; Joelson Rodrigues Miguel ${ }^{2}$

\begin{abstract}
Resumo: As práticas pedagógicas significativas têm um papel fundamental na tomada de consciência dos professores, além de promover uma autorreflexão capaz de oportunizar uma compreensão sobre aspectos facilitadores do ensino e aprendizagem. O presente estudo objetivou uma discussão sobre as práticas pedagógicas na formação docente. A metodologia consistiu em revisão integrativa com base nos aportes teóricos de autores como: Alegro (2008); Ausubel (1968); Bizarro (2014); Breda (2016); Dalbosco (2003); Ferreira (2017); Freire (2006); Klausen (2017); Leme (2006); Paula e Bida (2019); Pelizzari (2002); Schön (2009); Silva (2016), dentre outros. Os resultados demonstraram que as transformações, em decorrência da globalização, tem afetado muito a educação, da forma como se vem praticando. Daí uma necessidade que a escola que tente empreender políticas públicas com finalidades educacionais mais compatíveis com as reais necessidades sociais.
\end{abstract}

Palavras-chave: Práticas pedagógicas; Formação docente; Necessidades sociais.

\section{Pedagogical Practices in Teacher Education}

\begin{abstract}
Significant pedagogical practices play a fundamental role in raising teachers' awareness, in addition to promoting self-reflection capable of providing an understanding of aspects that facilitate teaching and learning. The present study aimed at a discussion about pedagogical practices in teacher education. The methodology consisted of an integrative review based on the theoretical contributions of authors such as: Alegro (2008); Bizarro (2014); Breda (2016); Dalbosco (2003); Ferreira (2017); Klausen (2017); Leme (2006); Paula E Bida (2019); Pelizzari (2002); Schön (2009); Silva (2016), among others. The results showed that the transformations, as a result of globalization, have greatly affected education, in the way it has been practiced. Hence the need for schools to try to undertake public policies with educational purposes that are more compatible with real social needs.
\end{abstract}

Keywords: Pedagogical practices; Teacher training; Social needs.

\footnotetext{
${ }^{1}$ Mestrado em Educação pela Florida Christian University. Orlando-FL.

2 Doutorado em Ciências da Educação pela Universidade Autónoma de Asunción -PY. Pós-Doutorado pela Universidade Autónoma de Asunción -PY. Pós-Doutorando pela Florida Christian University. Participa dos programas de Educação EAD, Education Without Borders Program. Orientador de Dissertações e Teses pela Florida Christian University. Autor correspondente: joelsonrmiguel@ hotmail.com.
} 


\section{Introdução}

Uma das principais discussões desencadeadas no campo educacional diz respeito ao processo de ensino e as dificuldades encontradas pelo docente em sua prática pedagógica. Esta é uma problemática que incide diretamente sobre a aprendizagem dos estudantes. Nesse contexto, a prática docente tem um papel definidor para alcançar o aluno em seus interesses e necessidades, considerando ainda as diferenças individuais presente em toda escola. Este é um desafio para a formação docente, um exercício constante à inovação através da arte de ensinar para o protagonismo.

A função docente molda-se dentro do que exige a educação, e esta consiste na busca pelo aperfeiçoamento da prática educativa, uma construção essencial na conquista pelo aprimoramento do docente. Ou seja, para que o professor consiga transmitir a matéria de estudo ou valor formativo, da melhor forma possível ao aluno, é importante que existam meios propícios ao processo de ensino-aprendizagem, pois possibilitará a absorção positiva no processo de aprendizagem.

A metodologia adotada neste estudo constou de uma revisão integrativa que nos permitiu anunciar novas informações a respeito do assunto ora tratado. Utilizou-se como base para os aportes teóricos, autores como: Alegro (2008); Ausubel (1968); Bizarro (2014); Breda (2016); Dalbosco (2003); Ferreira (2017); Freire (2006); Klausen (2017); Leme (2006); Paula E Bida (2019); Pelizzari (2002); Schön (2009); Silva (2016), dentre outros.

Ante o exposto nos indagamos: Qual a importância das práticas pedagógicas na formação docente?

\section{A Importância da Utilização de Práticas Pedagógicas na Formação Docente}

As práticas pedagógicas significativas têm um papel fundamental na tomada de consciência dos professores e promove a autorreflexão dos mesmos, uma vez que lhes oportuniza uma compreensão sobre aspectos da prática pedagógica de forma a facilitar o ensino e aprendizagem e, assim, o aperfeiçoamento do ensino poderá ser buscado tendo como referência esta concepção teórica.

De acordo com Alegro (2008): 
[...] a teoria da aprendizagem significativa, ao descrever o processo de aprendizagem, no qual destaca o conhecimento prévio do aprendiz como o fator isolado mais importante na determinação do processo de ensino, oferece uma contribuição fundamental para o reconhecimento do aluno como sujeito que aprende; das possibilidades de mudança por meio do aprendizado; da necessidade de não transformar diferenças sociais, econômicas, culturais e cognitivas em desigualdades escolares (ALEGRO, 2008, p. 15-16).

Para que uma aprendizagem se torne significativa é necessário que o professor aceite o conhecimento prévio do aluno fazendo-o incorporar o novo conhecimento com o que ele já conhece. A partir daí, cria significado a aquisição de tal conhecimento através da relação com seu saber prévio. Mas, se isso não for feito, ela se torna mecânica ou repetitiva, uma vez que se produziu menos essa incorporação e atribuição de significado, e o novo conteúdo passa a ser armazenado isoladamente ou através de associações arbitrárias na estrutura cognitiva.

Em contribuição com o exposto Pelizzari et al (2002) diz que:

Quando o conteúdo escolar a ser aprendido não consegue ligar-se a algo já conhecido, ocorre o que Ausubel chama de aprendizagem mecânica, ou seja, quando as novas informações são aprendidas sem interagir com conceitos relevantes existentes na estrutura cognitiva (PELIZZARI et al, 2002, p. 38).

Desta forma, o sujeito acaba aprendendo fórmulas, leis, conceitos e informações em diversas áreas da vida, porém esquece após a avaliação, o que significa dizer que o aluno memorizou apenas para a prova, os processos de construção do saber não acontecem devido à ineficiência da prática pedagógica de não oportunizar o que o aluno já conhece ao saber sistemático da escola, e assim atribuir sentido para sua vida e, em muitos casos transformá-la com as experiências e correlações da sala de aula.

É preciso entender que no processo de ensino e aprendizagem o que deve contar é a participação do aluno nesse processo, que estes alunos sejam tratados como seres sociais, com habilidades e experiências significativas que serão importantes para que o professor possa planejar sua aula, desconsiderar o aluno no planejamento é não enxergá-lo como protagonista não só de sua história, mas como principal motivador para a construção do plano de aula do professor, afinal é para eles e com eles que a educação precisa ser pensada.

As ideias de Ausubel se caracterizam por estarem fundamentadas em uma reflexão específica sobre a aprendizagem escolar e o ensino, em vez de tentar apenas generalizar e transferir à aprendizagem escolar conceitos ou princípios explicativos tirados de outras situações ou contextos de aprendizagem. Para haver aprendizagem significativa são necessárias 
duas condições, a priori, o estudante precisa estar disposto para aprender, se a pessoa desejar memorizar o conteúdo arbitrária e literalmente, a aprendizagem será mecânica (GAUTHIER; BISSONNETTE; RICHARD, 2013).

Em segundo lugar, o conteúdo escolar a ser aprendido deve ser potencialmente significativo, ou melhor, tem que ser coeso e psicologicamente significativo, a acepção lógica depende unicamente da natureza do conteúdo, e o significado psicológico é uma experiência que cada sujeito possui. Cada aprendiz faz uma filtragem dos conteúdos que têm ou não significado para si mesmo.

A aprendizagem envolve uma variedade de questões e condições básicas, elas podem ser estabelecidas por meio da motivação, do interesse, da habilidade de partilhar experiências e de interatuar com os distintos contextos. Sendo assim, o os educadores têm o desafio de despertar o interesse para que a aprendizagem possa ocorrer de forma significativa, pois esse compromisso com um ensino e aprendizagem embasado na criticidade e no diálogo tornam as aulas interessantes, com conteúdos relevantes para que possam ser partilhados em experiências extraescolares.

$\mathrm{Na}$ opinião de Klausen (2017) a família também tem papel fundamental na aprendizagem significativa, pois:

Considerando que a escola deve trabalhar com o conhecimento prévio e a experiência do aluno, a família precisa contribuir no processo, educando, assumindo responsabilidades e atuando em parceria com a escola, ressaltando que cada uma das partes deve preservar suas características próprias. Essa ação conjunta facilitará a adaptação do educando no espaço escolar e sua relação com a aprendizagem, possibilitando uma educação satisfatória (KLAUSEN, 2017, p. 6404- 6405).

De fato, a escola e a família precisam buscar parcerias, de maneira que os alunos tenham chances de construir um perfil de pessoa capaz de viver e conviver em situações novas e agradáveis para eles. Julga-se necessário que reflitamos sobre a prática de ensino dos educadores, uma vez que, professores por motivos diversos de condições de trabalho, incertezas na profissão e outras questões tem deixado de lado o contexto do aluno, a realidade que eles vivem, apresentando assim conteúdos desconectados das experiências dos mesmos.

Isso é uma realidade brasileira, porém há que se pensar que a educação precisa ser levada a sério não só por parte da instituição escolar, mas da família, sociedade, governo e todos que desejam uma educação reflexiva, que pense cada vez mais no aluno, fazendo-o protagonistas e 
não meros receptores ou coadjuvantes, é preciso propiciar ao estudante um ambiente livre das memorizações, das repetições, do tradicionalismo.

Para Leme (2006) é necessário perceber quem são esses alunos, seus sonhos, anseios e, assim, conseguir delinear atividades na qual eles se sintam estimulados a participarem das aulas. A função do professor é de enorme importância, seu papel é criar um ambiente propício à assimilação do saber, facilitando o processo de ensino e aprendizado. A aprendizagem significativa pode ser a condição efetiva para conseguir esse objetivo, assegurando ao aluno a versatilidade de operar com independência em diferentes contextos.

Como já foi mencionado por Paulo Freire, só existe aprendizagem quando de fato houver participação consciente do discente, como sujeito do processo. Outro ponto que é importante destacarmos é que quando o aluno assume o papel de sujeito cognoscente, tendo como mediação do professor, esse último ator passa a fazer autoavaliação, prática essa que carece de ser feita por todos os professores, ao se autoavaliar o educador analisa sua prática pedagógica e assim poderá caminhar com mais tranquilidade, mas, essa reflexão é continuada, e deve permanecer em atividade.

Para o aluno essa autocrítica por parte do educador pode trazer bons resultados, pois o aluno percebe quando o professor está ciente do desenvolver de uma aula, hoje os alunos não são os mesmos dos tempos de outrora e com a inovação tecnológica tudo se intensificou, atualmente se o professor não estiver preparado para lidar com transformações e questionamentos cada vez mais pertinentes dos alunos e bem provável que esse docente seja mais um profissional que transmite os conteúdos que age por meio de uma estratégia de ensino engessada e memorística. É preciso também levar em considerações os vários outros atores no processo de ensino e aprendizagem.

Como descrito por Ferreira (2017) quanto ao processo educativo se fazer com a participação de outros atores:

[...] o processo educativo não ocorre apenas entre o professor e o aluno, mas, embora estes sejam os atores principais, os demais agentes administrativos, os pais e a comunidade escolar como um todo também são agentes que atuam e influenciam o processo de aprendizagem (FERREIRA, 2017, p. 16).

Neste sentido, é importante destacar que a administração escolar também esteja aberta para a constituição de novas competências e sejam capazes de delegar competências e consentir que outras pessoas participem do processo decisório passando assim a ocupar um papel de 
gestor ao invés de uma atitude autoritária. Diferentes medidas carecem ser adotadas para se obter o sucesso no processo de ensino e aprendizagem merecendo evidência o processo de formação continuada do docente e o seu papel como mediador do conhecimento, sempre procurando considerar as experiências trazidas pelos discentes para o contexto escolar.

Todos do contexto escolar podem contribuir com o ensino e aprendizagem, uma vez que, o compromisso com uma educação de qualidade e pautada no aluno é tarefa não só do professor, mas da família, comunidade, da sociedade, do estado, mesmo que o docente tenha o papel de mediar os processos de construção do conhecimento em sala de aula, não significa dizer que apenas ele pode contribuir na socialização do saber desse aluno. A educação se faz com o apoio de todos, pois não é um espaço isolado da sociedade.

A educação é entendida por Dalbosco (2003) como:

Um processo recíproco, espontâneo e assistemático de ensino-aprendizagem entre duas ou mais pessoas. O característico da educação é o fato de ela dizer respeito à interação entre pessoas e de não se limitar ao processo formal de ensino-aprendizagem que ocorre no universo escolar ou universitário. Assim, é um processo interativo amplo que ocorre, por exemplo, na relação entre pais e filhos, entre grupos de convivência, de trabalho, etc (DALBOSCO, 2003, p. $38)$.

O aluno é um ser social e político que precisa do apoio de todos no processo de construção do saber. Embora seja responsabilidade da instituição escolar explicitar o tipo de cidadão que deseja construir e que interferências serão imprescindíveis para que este cidadão possa de fato interatuar no seu meio social. Essa tarefa deverá ser partilhada com todos os envolvidos com situações de ensino-aprendizagem. Professores, alunos, pais e sociedade necessitam refletir sobre o tipo de cidadão que se quer constituir na escola e na sociedade.

Desta forma, a instituição escolar torna-se um campo fértil, adequada às aprendizagens tanto de alunos quanto dos educadores. Neste âmbito, considera-se como importante e necessária a reflexão sobre as situações de colaboração e de respeito que precisam existir para que todos os sujeitos participantes do meio educativo de fato atuem como sujeito e não como meros expectadores do processo educativo.

Promover a aprendizagem significativa é parte de um projeto educacional libertador, que objetiva a formação de cidadãos conscientes de suas vidas e dos papéis que representam nelas. É inviável ensinar liberdade, limitando ideias, silenciando ou oprimindo sujeitos no processo de construção do conhecimento e ditando "verdades absolutas". Ao perceber essas 
atitudes os professores precisam iniciar um real processo de transformação de sua prática (BIZARRO, 2014).

O currículo tem uma função extremamente importante para o desenvolvimento das aulas, pois é necessário um currículo que atenda as necessidades dos alunos, suas especificidades, anseios, o currículo deve ser bem estruturado e isso é oportunizado quando todos do setor escolar se propõem a trabalhar em prol de uma educação que vise o desenvolvimento do professor e do aluno, da comunidade e da sociedade.

Diante dessa literatura das práticas pedagógicas significativas e formação docente ficou evidente que o aprendizado se efetiva apenas se houver reflexão e oportunidade para que os alunos se posicionem em que seus questionamentos e sugestões sejam considerados, de maneira que a análise sirva para a elaboração pessoal do conhecimento.

De acordo com Paula e Bida (2008) um comportamento antidemocrático no campo da educação afeta o desenvolvimento do alunado, pois:

[...] ao ingressarem na instituição escolar, são obrigados a deixar para trás o seu cotidiano em vista da estrutura regrada da escola que é um local onde, na maioria das vezes, não há espaço para a emoção e os sentimentos. Esse choque entre o dia-a-dia juvenil e o enquadramento escolar não é nada motivador porque limita a criatividade e o espírito crítico. As formas de perceber e viver o conteúdo que envolve a escola e o mundo exterior são muito diferentes (PAULA; BIDA, 2008, p. 5).

Nesta perspectiva, quando o educador exibe o conteúdo de forma descontextualizada, o aluno não problematiza e o conteúdo acaba passando de forma acrítica, esse conteúdo não vai surtir efeito na vida do aluno, por que o mesmo não se apropriou do conhecimento desse conteúdo, apenas ouviu, não dialogou sobre e isso tem uma gravidade enorme, pois haverá o momento que o estudante vai precisar desse estudo e não conseguirá solucionar o problema.

Portanto, é fundamental estudar bem o conteúdo, usar textos curtos e fazer questionamentos que conduzam à reflexão. Para problematizar sobre esses textos com os alunos pode ser feito uma pergunta bem elaborada para verificar se o aluno realmente compreendeu o conteúdo, além disso, é possível fazer um recorte de jornal, uma fotografia, um vídeo ou uma pequena história, uma cena de um filme. Reconhecer os conhecimentos dos educandos e dialogar com eles é de suma importância na construção do conhecimento, tanto do professor, quanto do aluno.

O profissional docente é cobrado diariamente a assumir novos papéis, que sejam condizentes com o que realmente está acontecendo na sociedade ou se está contemplando os

709 Id on Line Rev. Mult. Psic. V.14, N. 51 p. 703-715, Julho/2020 - ISSN 1981-1179

Edição eletrônica em http://idonline.emnuvens.com.br/id 
alunos, a profissão docente é carregada de determinações que exigem cada vez mais do educador. Com o advento de novas formas de aquisição do conhecimento as exigências se fazem presente, uma vez que as informações contidas nesses novos meios de obtenção do saber muitas vezes apresentam conceitos errôneos e não exploram como deveriam a objetividade e imparcialidade, é neste momento que entra o docente, para mediar essa construção do saber. Nesse universo de transformações é importante considerar que os professores assumem a função de intervenção, pois ele não é imune aos processos socais e as mutações que ocorrem socialmente (SILVA, 2016).

No que refere a postura do profissional docente no atual contexto social é importante mencionar que cada vez mais as informações se dispersam com maior rapidez o que podemos considerar que permanentemente esses profissionais repensem a sua prática pedagógica, olhando em sua volta o quantitativo de oportunidades e ferramentas úteis para uma boa aula, para o processo de constituição do saber. O mundo está em processo de transformação acelerado o que hoje é novo amanhã pode não ser mais, esta é uma premissa que é percebida não só dentro do contexto educacional, mas na sociedade.

Portanto, saber como labora essas transformações, e como isso pode modificar o modo de ser e agir das pessoas é um dos compromissos do novo profissional da educação, por isso que mais do que nunca, o docente necessita estar sempre atualizado e informado, não somente no que diz respeito aos acontecimentos e fatos do mundo, mas, especialmente, relativos aos conhecimentos pedagógicos e curriculares e às novas disposições educacionais. Perante este panorama é possível entendermos que uma análise por parte do professor e em buscar novos mecanismos auxilia na sua prática pedagógica e onde a práxis pode ser contemplada.

Destarte, contribuindo com esta concepção Possato, Monteiro e Guimarães (2019) diz que:

Para atingir esses objetivos, o docente deve saber fazer a mediação da
aprendizagem; ter conhecimento e habilidade técnica relacionados às
disciplinas ensinadas; manter postura de integração em relação à sociedade;
envolvimento com processos produtivos e mercado de trabalho. Deve adquirir
uma visão ampla a respeito do papel social da escola de ensino profissional,
ter prática reflexiva e implicação crítica (POSSATO; MONTEIRO;
GUIMARÃES, 2019, p. 153).

No dia a dia de suas aulas o educador precisa atualizar seus métodos tendo como objetivo alcançar as expectativas dos alunos, mas o principal objetivo é construir conhecimento por meio de novas perspectivas que estão presentes na sociedade em que os profissionais saem

710 Id on Line Rev. Mult. Psic. V.14, N. 51 p. 703-715, Julho/2020 - ISSN 1981-1179 
da zona de conforto, pois com recursos tradicionais a educação destes não irá ser o suficiente para que eles compreendam por outras vertentes o conteúdo que está sendo trabalhado em sala, como ele pode ser aplicado no seu cotidiano, uma vez que esses novos recursos potencializadores fazem parte da vida das pessoas, os smartfones, tablets, notebooks, TV digital, essas ferramentas podem ter aparentemente finalidades distintas do educar, mas são indispensáveis no contexto escolar, com as novas redes de interação é possível ensinar e aprender com os alunos.

Os novos aplicativos que estão dispersos no dia a dia podem produzir conhecimento e inovar as concepções dos alunos para o uso responsável desses aplicativos, pois entendam que esses canais midiáticos como (WhatsApp, Facebook, Instagram, Youtube, Twitter) são carregados de potencialidades, porém se usadas de forma errada pode provocar efeitos irreparáveis, por isso se faz necessário o seu uso dentro da sala de aula com a proposta de trazer inovação para este universo tão heterogêneo, como também para auxiliar os alunos a refletirem sobre o objeto.

O uso destas ferramentas por muitas vezes se torna em um grande desafio, pois muitos profissionais ainda não compreendem de forma crítica essas novas ferramentas, como também não sabem utilizar, o que torna um desafio para os mesmos e, além disso, por onde começar? Como começar a introdução desses recursos? Entende-se que não é uma tarefa fácil, porém não é diante esses aspectos que são normais que eles irão ignorar a funcionalidade e importância desses dispositivos. Este deve ser entendido como parte do desenvolvimento profissional, que acontece ao longo da ação docente, podendo permitir um sentido inovador à prática pedagógica, contextualizando novas ocorrências e ressignificando a ação docente (SCHÖN, 2009).

Para que as alterações que acontecem na sociedade contemporânea possam ser acompanhadas é necessário um novo profissional do ensino, isto é, um profissional que aprecie a investigação como tática de ensino, que suscite a reflexão crítica da prática e que esteja sempre atento com a formação permanente. Uma formação que faça desse novo profissional um sujeito não mais tradicional ou habituado com os mesmos mecanismos de ensino, mas que transcenda na sua busca do querer mais, querer mais da educação, querer mais dos alunos numa postura crítica reflexiva.

Através da pesquisa, do estudo, da reflexão, do constante contato com novas concepções que o professor poderá proporcionar aos seus discentes múltiplos formas de pensar o conteúdo abordado, o educador ao mudar permite que seus conceitos também se reestruturem agregando 
ao seu contexto pessoal e profissional novas proposições sobre o si e sobre a sua atuação no campo educacional.

No que se refere à pesquisa, para Breda et al (2016):

Para que o professor incorpore a pesquisa em sua prática é necessário que ele tenha desenvolvido as competências para isso em sua formação. Daí a necessidade de, nos currículos das instituições formadoras, estar presente a meta de se desenvolverem atitudes investigativas nos futuros docentes (BREDA et al, 2016, p. 110).

Percebe-se que o fato dos professores não terem sido estimulados à investigação dificilmente terá interesse de ir a busca destes, porém acabam sendo desafiados durante a sua atuação em sala de aula, e, conforme as transformações acontecem as exigências aumentam, podemos dizer que o ato de ensinar atualmente estar cada vez mais desafiador e carregado de novas concepções que antes eram pouco exploradas, a exemplo de novas possibilidades de ensino, do papel do professor e dos recursos pedagógicos que serão utilizados na instituição escolar.

Fica mais abstruso de o docente mudar seu modo de refletir o fazer pedagógico se o mesmo não tiver a chance de vivenciar novas experiências, novas pesquisas, novas configurações de ver e pensar a escola. Para tanto, faz-se necessário que os educadores estejam sempre renovando seu modo de ensinar, pesquisar, aprendendo ao longo da vida, nenhum profissional estar pronto, todos os profissionais carecem de entender que a sua atuação dentro da sala e na sociedade tem um papel extremamente importante e a sua ressignificação é um processo diário.

O processo de desenvolvimento das redes de informação faz com que todas as pessoas encontrem formas de entender as novas demandas da sociedade, dos cargos nas empresas, da forma como esse indivíduo irá lidar com as transformações sociais e como estes novos recursos tecnológicos poderão facilitar e resolver problemas em curto espaço de tempo, sendo esta uma das atribuições das ferramentas digitais, hoje é possível entrar em contato com pessoas de diversos lugares com apenas alguns cliques, dotado de funções cada vez mais revolucionárias os dispositivos digitais tem redescoberto um novo modo de pensar não só a ampliação das empresas como também o processo de ensino e de aprendizagem (NONAKA; TAKEUCHI, 2004).

Por fazer parte da vida pessoal e social dos indivíduos torna-se imprescindível buscar nos recursos digitais formas e caminhos que possam diversificar o universo educacional, sem

712 Id on Line Rev. Mult. Psic. V.14, N. 51 p. 703-715, Julho/2020 - ISSN 1981-1179 Edição eletrônica em http://idonline.emnuvens.com.br/id 
que o aluno sinta-se desmotivado ao estar na sala de aula, pois o processo de ensino e de aprendizagem não é uma tarefa que pode ser realizada rapidamente, visto que é preciso respeitar o ritmo e singularidade de cada aluno.

De acordo com a concepção de Motta (2018, p. 43-44) é necessário que o docente tenha uma formação comprometida com a produção e transformação de conhecimento, tornando-o capaz de ir mais além de seus condicionantes. Esta formação é uma formação desprendida daquela formação em que o professor é o detentor do conhecimento e em que o aluno não pode dialogar apresentando seus questionamentos, dúvidas e apresentando sugestões não se faz educação sozinha, e ensinar não é o aluno ficar quieto na sala e não poder questionar sobre determinado conteúdo, ocorrência, percepção do educador.

Essa ação inadequada do professor afeta a maturação dos assuntos por parte dos alunos e atinge drasticamente seu processo de exercício de cidadania, visto que o aprendizado em sala ao não ser compreendido pelo discente as dúvidas permanecem e são levadas adiante se reproduzindo de forma equivocada. Nesta perspectiva, os profissionais docentes estão sendo desafiados a aprender a aprender, e isso só será possível se os mesmos entenderem a necessidade e importância que a formação permanente tem para sua vida profissional e para a constituição dos conhecimentos dos alunos.

\section{Considerações finais}

Enfim, o que se objetiva numa formação docente é que se possa assegurar um ensino de qualidade aos educandos, um ensino que os faça serem protagonistas de suas histórias, que construam juntamente com a mediação do educador emancipador e libertador o processo de reflexão e crítica alicerçado numa metodologia que envolva o aluno, que os faça sentirem especiais cada um com sua particularidade, e que o seu conhecimento do cotidiano seja valorizado e aproveitado dentro e fora da sala de aula.

Vive-se um tempo em que a escola vem sendo questionada quanto ao seu papel social e educativo sob o contexto de discussões que possam direcionar os caminhos a seguir, embora diversas questões como a econômica, social, cultural, política ou tecnológica sejam as norteadoras. As transformações, em decorrência da globalização, tem afetado muito a educação, da forma como se vem praticando. Com isso, solicita-se da escola que tente empreender finalidades educacionais mais compatíveis com o interesse da política capitalista. 
Consequentemente, a escola carece de políticas públicas mais alinhadas com as reais necessidades sociais.

Nessa perspectiva, é importante frisar que o papel social da escola e dos profissionais docentes é contribuir para formação de novos sujeitos críticos e reflexivos que saibam atuar na sociedade com uma consciência crítica e para a formação do cidadão participante da vida social.

\section{Referências}

ALEGRO, Regina Célia. Conhecimento prévio e aprendizagem significativa de conceitos históricos no Ensino Médio. 2008. 239f. Tese (Programa de Pós-Graduação) - Universidade Estadual Paulista. Marília/São Paulo. 2008.

AUSUBEL, D.P. Educational Psychology: Cognitive View. New York: Holt, Rinehart and Winston, Inc., 1968.

BIZARRO, Atila Cristiano. A atuação do educador no programa mais educação em uma escola pública estadual do Rio Grande do Sul. Dissertação (Programa de Pós-Graduação) Universidade do Vale do Rio dos Sinos - UNISINOS. 2014. 116f. São Leopoldo, 2014.

BREDA, Adriana et al. A investigação como princípio educativo na formação de professores de Ciências e Matemática. Revista Caderno Pedagógico, Lajeado, v. 13, n. 1, 2016. Disponível em: http://www.univates.br/revistas. Acesso em: 16 maio 2019.

DALBOSCO, Cláudio Almir. Considerações sobre a relação entre filosofia e educação. In FÁVERO, Altair Alberto; DALBOSCO, Cláudio Almir; MÜHL, Eldon Henrique. (Org) Filosofia, educação e sociedade. Passo Fundo: UPF, 2003.

FERREIRA, Maria Bernadete da Silva. Estudo sobre as competências para ensinar: diálogos com uma professora transformadora. 2017. 49f. Monografia. Universidade Federal Fluminense. Santo Antônio de Pádua, 2017.

FREIRE, P. Pedagogia da autonomia (34a ed.). São Paulo: Paz e Terra, 2006.

GAUTHIER, Clermont; BISSONNETTE, Steve; RICHARD, Mario. Ensino explícito e desempenho dos alunos: a gestão dos aprendizados. Editora Vozes Limitada, 2013.

KLAUSEN, Luciana dos Santos. Aprendizagem significativa: um desafio. IV Seminário Internacional de representações sociais, subjetividade e educação - SIRSSE. Revista Educere, 2017. Disponível em: http://educere.bruc.com.br/arquivo/pdf2017/25702_12706.pdf. Acesso em: 07 Fev. 2019.

LEME, Rogério. Avaliação de desempenho com foco em competência. Qualitymark Editora Ltda, 2006. 
PAULA, Gilma Maria Carneiro; BIDA, Gislene Lossnitz. A importância da aprendizagem significativa. $2008 . \quad$ Disponível em: http://www.diaadiaeducacao.pr.gov.br/portals/pde/arquivos/1779-8.pdf. Acesso em: 17 Fev. 2019.

PELIZZARI, Adriana et al. Teoria da aprendizagem significativa segundo Ausubel. revista PEC, v. 2, n. 1, p. 37-42, 2002.

POSSATO, Alvaro Bubola; MONTEIRO, Patrícia Ortiz; GUIMARÃES, Josiane Cristina. Perfil sociodemográfico e identidade dos docentes da educação profissional na área de tecnologia da informação e comunicação. Boletim Técnico do Senac, v. 45, n. 1, 2019.

SCHÖN, Donald Alan. Educando o profissional reflexivo: um novo design para o ensino e a aprendizagem. Penso Editora, 2009.

SILVA, Sônia Cristina. Processos mediadores desenvolvidos pelo professor pedagogo na Escola Pública Estadual do Paraná: novas dimensões de atuação. Dissertação (Mestrado em Educação) - Universidade Federal do Paraná, Curitiba/PR, 2016.

Como citar este artigo (Formato ABNT):

SILVA, Cleyde Nascimento da; MIGUEL, Joelson Rodrigues. Práticas Pedagógicas na Formação Docente. Id on Line Rev.Mult.Psic., Julho/2020, vol.14, n.51, p.703-715. ISSN: 1981-1179.

Recebido: 12/07/2020;

Aceito: 19/07/2020. 